
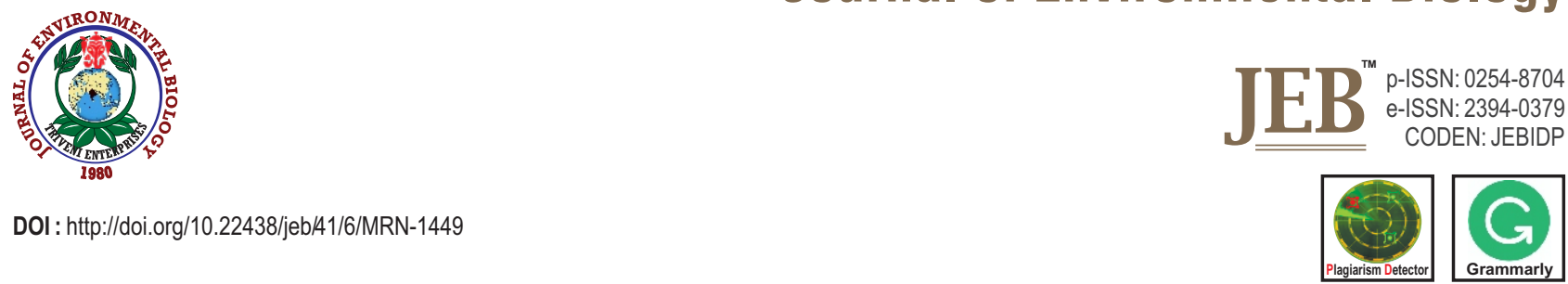

\title{
Influence of chitinase production on the antagonistic activity of Trichoderma against plant-pathogenic fungi
}

\author{
Y.S. Mazrou ${ }^{1,2}$ A.H. Makhlouf ${ }^{3}$, M.M. Hassan ${ }^{4,5 *}$ A. Baazeem ${ }^{4}$, A.A. Hamad ${ }^{4,5}$ and M.M. Farid ${ }^{6}$ \\ ${ }^{1}$ Department of Business Administration, Community College, King Khaled University, Abha-62529, Saudi Arabia \\ ${ }^{2}$ Department of Agriculture. Economics, Faculty of Agriculture, Tanta University, Tanta-3111, Egypt \\ ${ }^{3}$ Department of Botany, Faculty of Agriculture, Menoufia University, Menoufia-32514, Egypt \\ ${ }^{4}$ Department of Biology, Faculty of Science, Taif University, Taif 21944, Saudi Arabia \\ ${ }^{5}$ Department of Botany and Microbiology, Faculty of Science, Cairo university, Cairo 12612, Egypt \\ ${ }^{6}$ Department of Genetics, Faculty of Agriculture, Kafrelsheikh University, Kafr El-Sheikh-33516, Egypt \\ *Corresponding Author Email : khyate_99@yahoo.com
}

\section{Abstract}

Aim: The present study aimed to investigate the antagonistic activity of Trichoderma strains with high chitinase production against some plant pathogenic fungi.

Methodology: A total of twenty-four Trichoderma isolates were extracted from soil samples collected at different geographical locations in Egypt and Saudi Arabia. These isolates were screened for their chitinase production ability using colloidal chitin media. Six isolates with high chitinase ability were identified as $T$. harzianum by internal transcribed spacer (ITS) region sequencing. These strains were tested for their ability to degrade chitin into N-acetyl- $\beta$-D-glucosaminidase. Finally, the biocontrol activities of these Trichoderma strains against pathogenic fungi were tested by dual culture technique.

Results: The maximum activity among the chitinolytic enzymes was 0.051 units $\mathrm{ml}^{-1}$ in Trichoderma strain ABSA19, which showed an activity comparable to the control: pure enzyme, $\left(0.047\right.$ units $\left.\mathrm{ml}^{-1}\right)$. The lowest activity $\left(0.014\right.$ units $\left.\mathrm{ml}^{-1}\right)$ was found in Trichoderma strain MEG2. In dual culture, Trichoderma strain ABSA19 exerted the highest antagonistic activity in addition to hyphal intertwining and degradation using scanning electron microscopy. Finally, 11 inter simple sequence repeats (ISSR) primers were used to evaluate the genetic polymorphism among Trichoderma strains, which yielded 133 bands with fragment sizes of 130-3400 bp, 47 (35.3\%) of which were polymorphic.

Interpretation: The current study confirms the existence of several useful Trichoderma strains with the highest chitinase activity and antagonistic activity against some pathogenic plant fungi that may have a super potential for application in biological control of plant diseases.

Key words: Antagonistic activity, Chitinase assay, Genetic polymorphism, Internal transcribed spacer, Trichoderma strains

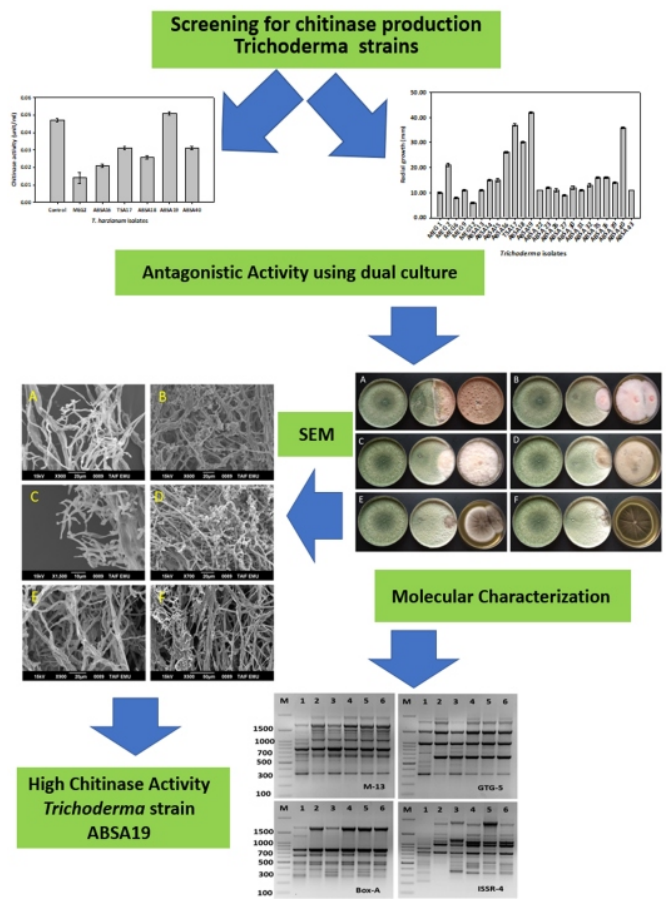

How to cite : Mazrou, Y.S., A.H. Makhlouf, M.M. Hassan, A. Baazeem, A.A. Hamad and M.M. Farid: Influence of chitinase production on the antagonistic activity of Trichoderma against plant-pathogenic fungi. J. Environ. Biol., 41, 1501-1510 (2020). 


\section{Introduction}

Trichoderma spp. are among the most important fungi used for the biological control of plant pathogenic fungi in soil. The important roles of these fungi are ability to synthesize many enzymes, such as chitinase, cellulase and protease, which enable them to control plant diseases (Hassan et al., 2013, 2014; Mazrou et al., 2020b). Trichoderma species exert multiple methods of biological control that can be employed against plant pathogens. These methods include mycoparasitism, antibioticmediated suppression, production of lytic enzymes and other byproducts, competition for nutrients, or induction of host resistance (Navazio et al., 2007; Goswami et al., 2008; Vinale et al., 2009; Karlsson et al., 2010; Hassan et al., 2019). Chitinases are chitin-degrading enzymes that are widely distributed in nature and hydrolyze the $\beta$-1,4-glycosidic bonds between the $\mathrm{N}$-acetyl glucosamine residues of chitin (Hassan 2014; Aggarwal et al., 2015). The chitinases from Trichoderma species belong to glycosyl hydrolase family, and can be grouped into categories III and V. Various chitinase genes from Trichoderma spp. have been reported and characterized worldwide with emphasis on their roles in biological control strategies (Binod et al., 2007; Hassan et al., 2014; Abd-El-Kareem et al., 2019). Substrates like solid chitin, colloidal chitin, or red chitin can be used to evaluate chitinase activity. In addition, chitinase activity can easily be estimated by colorimetric quantification method (Hassan, 2014). However, since chitinase activity is exhibited as a reaction to pathogens, the colorimetric method cannot be readily applied for the identification of strains with low chitinase production.

Therefore, simpler and faster tests, such as those using colloidal chitin in solid media, need to be developed. These assays should be designed so that chitinase activities of known microbes can be visualized, for instance by the formation of a clear halo due to chitin digestion (Schickler et al., 1988; RojasAvelizapa et al., 2001; Agrawal and Kotasthane 2012; Mazrou et al., 2020b). The most sensitive detection techniques usually require more expensive substrates. Therefore, these assays are better suited for characterizing all proteins expressed in each microbial strain, as opposed to the selective detection of chitinolytic strains. Recently, some researchers (Parmar et al ., 2015; Mazrou et al., 2020b) have proposed a sensitive, reproducible, easy, and cost-effective method for evaluating chitinolytic properties of Trichoderma isolates from India and Egypt against some pathogens. In view of the above, the aim of the present study was to find novel biocontrol strains of Trichoderma and investigate the relationship between antagonistic activity of Trichoderma strains and chitinolytic enzyme production.

\section{Materials and Methods}

Isolation and identification of Trichoderma strains: Twentyfour Trichoderma isolates were extracted from soil samples collected from different geographical locations in the Menoufia Governorate of Egypt and the cities of Taif and Abha in the Kingdom of Saudi Arabia. The rhizospheres from healthy tomato plants were used in accordance with the protocol outlined in Hassan et al. (2014). The chitinase detection medium used for inducing chitinase activity was prepared according to the method described by Agrawal and Kotasthane (2012) using Rhioctonia solani as a negative control and Bacillus as a positive control. Chitinase detection medium was supplemented with $4.5 \mathrm{~g}$ of colloidal chitin. Colloidal chitin was prepared from commercial chitin (Himedia, Mumbai, India). As reported by Roberts and Selitrennik (1988), the supplemented colloidal chitin acts as the sole carbon source in the chitinase assay medium. The chitinase detection medium was poured into ten different Petri plates (five represent negative control and five represent positive control) and inoculated with fresh fungal cultures. All treatments were incubated for two days at $28^{\circ} \mathrm{C}$, and the formation of colored zones was tracked to test the Trichoderma isolates for chitinase activity.

Chitinase activity in Trichoderma isolates: Chitinolytic assays to check for intracellular chitinase production were performed twice in a total of ten-250 ml Erlenmeyer flasks, five as positive and five as negative control. The colloidal chitin broth medium was inoculated with fresh cultures of Trichoderma isolates and incubated for five days at $28^{\circ} \mathrm{C}$ with continuous shaking at 200 $\mathrm{rpm}$. The total chitinolytic and $\mathrm{N}$-acetyl- $\beta$-D-glucosaminidase activities of the filtrates obtained from ten cultures were then checked using ELISA reader $800^{\mathrm{TM}}$ TS Absorbance Reader (BioTek, Vermont, USA). These assays were performed while measuring the amount of reducing saccharides released from the colloidal chitin medium using a chitinase assay kit, catalog number CS0980 (Sigma-Aldrich, Louis, USA) according to the manufacturer's instructions.

Tests of antagonistic activity against pathogens with chitin cell walls: Biocontrol activities of Trichoderma strains with high chitinase activity (strains MEG2, ABSA16, TSA17, ABSA18, ABSA19 and ABSA40) were checked twice against the following pathogenic fungi in three replicates: Colletotrichum gossypii, Fusarium oxysporum, Fusarium fujikuroi, Rhizoctonia solani, Aspergillus calidoustus and Alternaria brassicicola by the dual culture technique using Czapeck-Dox agar medium as described by Fahmi et al. (2012). Pathogenic fungi were obtained from GeneBank of Biotechnology and Genetic Engineering Unit, Scientific Research Deanship, Taif University, Saudi Arabia.

\section{Sample preparation for scanning electron microscopy} (SEM): The parasitism exhibited by hyphal cells of Trichoderma strains towards those of the tested pathogens was studied in detail by SEM at the Electronic Microscope Unit, Faculty of Science, Taif University, according to protocols described in Hassan (2014). To obtain the sites of interaction of the hyphae with the pathogens used in the study, Trichoderma and each pathogen were grown on PDA at $28{ }^{\circ} \mathrm{C}$ for $48 \mathrm{hr}$, respectively. Trichoderma and the respective pathogens grew towards each other allowing their hyphae to interact with one another. After 48 $\mathrm{hr}$ of incubation, the early stages of interaction was studied under a light microscope. The interaction sites were marked, and $1 \mathrm{~cm}^{2}$ 
agar block was removed from the plate for SEM preparation. Mycelial samples from the region of interaction were fixed for 24 hr with vapors of glutaraldehyde and osmium tetroxide (3:1), airdried for $48 \mathrm{hr}$, and then coated with gold.

Extraction of DNA from Trichoderma isolates: Trichoderma isolates with high chitinase activity were transferred to CzapeckDox broth medium and maintained at $28^{\circ} \mathrm{C}$ for three days. Total DNA was then extracted from selected isolates using the Nour plant and fungi DNA extraction kit (Sigma, Canada) according to the manufacturer's instructions.

Molecular identification: Strain identification was based on the internal transcribed spacer 1 and 2 (ITS1 and ITS2) regions of the ribosomal RNA gene cluster sequences according to the method described by Hassan et al. (2014). All sequences were obtained by PCR and direct amplicon sequencing from the 5 ' and $3^{\prime}$ ends, using a 3130 Genetic Analyzer (Applied Biosystems, Waltham, MA, USA) at Macrogen Co., Seoul, South Korea. The sequencing data were compared with the GenBank database (http:/l www.ncbi.nlm.nih.gov/BLAST/), using the nucleotide BLAST program to identify homology between the PCR fragments and sequences in the GenBank database. The sequences were deposited in the National Center for Biotechnology Information (NCBI) GenBank database under accession numbers MK680260, MK680282, MK680283, MK680284, MK680285 and HM545086.

Inter simple sequence repeats (ISSR) analysis: A total of 11 ISSR primers (Lakhani et al., 2016) were used for Trichoderma genotyping, (Table 1). PCR amplifications were performed according to the method described by Hassan et al. (2019). ISSRPCR was performed in reaction mixture containing $1 \mu \mathrm{l}(20 \mathrm{ng})$ of genomic DNA, $12.5 \mu$ of GoTaq® Green Master Mix (Promega, Madison, WI, USA), $1 \mu$ of each primer ( $20 \mathrm{pmol}$ ) and deionized distilled water (up to a total volume of $25 \mu \mathrm{l}$ ). For DNA amplification, the tube contents were heated at $94^{\circ} \mathrm{C}$ for $10 \mathrm{~min}$ in a C1000 Touch ${ }^{\text {TM }}$ Thermal Cycler (Bio-Rad, Munich, Germany). Subsequently, Taq polymerase was added, followed by 35 cycles of 1 min at $94^{\circ} \mathrm{C}, 1.5 \min$ at $52^{\circ} \mathrm{C}$ and 2.5 min at $72^{\circ} \mathrm{C}$, with a final 7-min extension at $72^{\circ} \mathrm{C}$. Amplified DNA products were analyzed by electrophoresis in $2 \%$ agarose gels run in Tris/borate/EDTA buffer. The gels were stained with ethidium bromide $(5 \mu \mathrm{g} \cdot \mathrm{ml}-1)$. A 100 bp DNA Ladder RTU (GeneDireX®, München, Germany)
Table 1: ISSR Primers name and sequencing used in T. harzianum genotyping

\begin{tabular}{ll}
\hline Primers name & $\begin{array}{l}\text { Primers sequences } \\
\left(5^{\prime}-3^{\prime}\right)\end{array}$ \\
\hline ISSR-2 & GAG AGA GAG AGA GAG AA \\
ISSR-4 & GAG AGA GAG AGA GAG ATT \\
ISSR-11 & AGA GAG AGA GAG AGA GTT \\
ISSR-13 & AGA GAG AGA GAG AGA GG \\
ISSR-16 & GAG AGA GAG AGAG AGA C \\
ISSR-18 & TCT CTC TCT CTC TCT CC \\
ISSR-29 & ACA CAC ACA CAC ACA CT \\
ISG-4 & AGA GAG AGA GAG AGA GG \\
M-13 & GTT TTC CCA GTC ACG AC \\
Box-A1 & CTA CGG CAA GGC GAC GCT \\
GTG-5 & GTG GTG GTG GTG GTG \\
\hline
\end{tabular}

was used as a standard. DNA was visualized by UV illumination, and then photographed, using a Bio-Rad Gel Doc 2000.

Data analyses: The mean chitinase and antagonistic activities of six different strains against pathogens was compared using Oneway analysis of variance (ANOVA) as implemented in SPSS software, version 16. Mean treatment comparisons was conducted using Duncan's Multiple Range (Snedecor and Cochran 1989) at $\mathrm{P}=0.05$.

\section{Results and Discussion}

Trichoderma species are known as soil-borne fungi. Some of these species have important biotechnological applications due to their production of many enzymes, including cellulase and chitinase, which can act as biocontrol agents (Fahmi et al., 2016; Hassan et al., 2019). The antagonistic potential of Trichoderma species against diverse fungal phytopathogens has been reported by several researchers over the years (Fahmi et al., 2012; Hassan et al., 2014; Mazrou et al., 2020b). Trichoderma spp., particularly T. harzianum, shows significant variation among the strains with respect to their hostile activity and host range (Hassan, 2014; Parmar et al., 2015). Thus, new strains of Trichoderma spp. from the rhizosphere of host plant that have a possible biocontrol activity against some

Table 2: Comparison between Trichoderma isolates and similar strains in NCBI database and accession numbers

\begin{tabular}{llllll}
\hline $\begin{array}{l}\text { Trichoderma } \\
\text { strains }\end{array}$ & $\begin{array}{l}\text { Trichoderma } \\
\text { identification }\end{array}$ & $\begin{array}{l}\text { Accession } \\
\text { numbers }\end{array}$ & $\begin{array}{l}\text { Similarity } \\
\text { value (\%) }\end{array}$ & $\begin{array}{l}\text { Similar } \\
\text { strain }\end{array}$ & $\begin{array}{l}\text { Accession } \\
\text { numbers* }\end{array}$ \\
\hline MEG2 & T. harzianum & MK680260 & 98 & T. h-LWU_41 & MK299140 \\
ABSA16 & T. harzianum & MK680282 & 100 & T. h-Cul2 & Mk673510 \\
TSA17 & T. harzianum & MK680283 & 100 & T.h-T50 & FJ884179 \\
ABSA18 & T. harzianum & MK680284 & 100 & T. h-Cul2 & Mk673510 \\
ABSA19 & T. harzianum & MK680285 & 100 & T. h-AT73 & Mk615748 \\
ABSA40 & T. harzianum & HM545086 & 100 & T. h-SVPP-20 & Ku215928 \\
\hline
\end{tabular}

${ }^{*}$ Strains accession numbers obtained from NCBI 
Table 3: Antagonistic potential of six Trichoderma isolates against Colletotrichum gossypii, Fusarium oxysporium, Rhizoctonia solani, Fusarium fujikuroi, Aspergillus calidoustus and Alternaria brassicicola

\begin{tabular}{lllllll}
\hline Trichoderma & \multicolumn{5}{c}{ Antagonistic potential inhibition \% } \\
\hline isolates & C. gossypii & F. oxysporium & R. solani & F. fujikuroi & A. calidoustus & A. brassicicola \\
\hline MEG2 & $70.8^{\mathrm{d}}$ & $83.7^{\mathrm{c}}$ & $79.8^{\mathrm{e}}$ & $81.2^{\mathrm{c}}$ & $87.8^{\mathrm{c}}$ & $89.2^{\mathrm{d}}$ \\
ABSA16 & $74.6^{\mathrm{c}}$ & $83.7^{\mathrm{c}}$ & $83.1^{\mathrm{b}}$ & $82.9^{\mathrm{b}}$ & $85.5^{\mathrm{a}}$ & $90.6^{\mathrm{c}}$ \\
TSA17 & $70.8^{\mathrm{d}}$ & $81.8^{\mathrm{d}}$ & $82.9^{\mathrm{c}}$ & $80.8^{\mathrm{d}}$ & $86.1^{\mathrm{d}}$ & $90.6^{\mathrm{c}}$ \\
ABSA18 & $74.6^{\mathrm{c}}$ & $85.6^{\mathrm{b}}$ & $81.4^{\mathrm{d}}$ & $80.8^{\mathrm{d}}$ & $88.5^{\mathrm{b}}$ & $88.1^{\mathrm{a}}$ \\
ABSA19 & $78.9^{\mathrm{a}}$ & $86.5^{\mathrm{a}}$ & $84.0^{\mathrm{a}}$ & $85.7^{\mathrm{a}}$ & $90.5^{\mathrm{a}}$ & $92.5^{\mathrm{a}}$ \\
ABSA40 & $76.8^{\mathrm{b}}$ & $85.6^{\mathrm{b}}$ & $81.4^{\mathrm{d}}$ & $81.2^{\mathrm{c}}$ & $88.5^{\mathrm{b}}$ & $91.2^{\mathrm{b}}$ \\
\hline
\end{tabular}

*Mean values within a column followed by the same letter are not significantly different at $\mathrm{P} \leq 0.05$

Table 4: Total number of scorable bands, polymorphism percentage and band size of ISSR markers obtained by 11 primers among T. harzianum samples

\begin{tabular}{lllll}
\hline $\begin{array}{l}\text { Primers } \\
\text { name }\end{array}$ & $\begin{array}{l}\text { Total scorable } \\
\text { fragments }\end{array}$ & $\begin{array}{l}\text { Polymorphic } \\
\text { fragments }\end{array}$ & $\begin{array}{l}\text { Polymorphism } \\
(\%)\end{array}$ & $\begin{array}{l}\text { Fragment size } \\
\text { range (bp) }\end{array}$ \\
\hline ISSR-2 & 11 & 2 & 18.2 & $490-1800$ \\
ISSR-4 & 18 & 8 & 44.4 & $210-3000$ \\
ISSR-11 & 11 & 4 & 36.4 & $400-2900$ \\
ISSR-13 & 9 & 3 & 33.3 & $200-2950$ \\
ISSR-16 & 12 & 6 & 50.0 & $130-2950$ \\
ISSR-18 & 14 & 5 & 35.7 & $300-2900$ \\
ISSR-29 & 12 & 7 & 58.3 & $250-2750$ \\
ISG-4 & 7 & 2 & 28.6 & $260-2900$ \\
M-13 & 14 & 3 & 21.4 & $320-2990$ \\
Box-A1 & 11 & 2 & 18.2 & $295-1700$ \\
GTG-5 & 14 & 5 & 35.7 & $310-2990$ \\
\hline Total & 133 & 47 & & \\
\hline
\end{tabular}

pathogens of the host in question must be explored to generate an industrially promising strain. This study was carried out to screen 24 native isolates of Trichoderma spp. (from the rhizospheric soil samples collected from Menoufia Governorate in Egypt and the cities of Taif and Abha in Saudi Arabia) for chitinase and biocontrol activities. All the Trichoderma strains were screened for chitinase production ability. Nonetheless, only six isolates secreted large amounts of chitinase, as assessed by colloidal chitin hydrolytic activity assay performed on agar plates. The highest chitinase production ability was detected in six Trichoderma strains (MEG2 from Menoufia, Egypt; TSA17 from Taif, Saudi Arabia; and ABSA16, ABSA18, ABSA19 and ABSA40 from Abha, Saudi Arabia), which were selected for determining chitinase activity. Among the Trichoderma isolates, strain ABSA19 formed the largest zone of inhibition, which exceeded $43 \mathrm{~mm}$ in diameter followed by TSA17 (37 mm) (Fig. 1 and S. 1).

These six isolates were identified using ITS region sequencing. The obtained sequences of the ITS regions were then subjected to BLAST search at NCBI database. These six strains with high chitinolytic activity were all identified as $T$. harzianum. Their sequences were deposited in the NCBI GenBank database (GenBank accession No. MK680260, MK680282, MK680283, MK680284, Mk680285 and Hm545086). Nucleotide comparisons of ITS regions among Trichoderma strains and other similar strains retrieved from NCBI revealed $100 \%$ identity between $T$. harzianum (ABSA16 and ABSA18) and T. harzianum Cul2 from the GenBank (Table 2). On the other hand, strains TSA17 and MEG2 exhibited $100 \%$ and $98 \%$ similarity with strain T50 and LWU-41 from the GenBank, respectively. Therefore, it is important to identify Trichoderma isolates to the species level. This is especially important because identification of these species at morphological level has been reported to be unreliable (Sharma et al., 2009; Shahid et al., 2013) due to high degree of similarity in morphology across strains. Molecular identification of Trichoderma strains to species level by ITS region sequencing was recently introduced as an effective alternative method for their accurate identification (Gajera and Vakharia 2010; Błaszczyk et al., 2011; Hassan et al., 2019; Mazrou et al., 2020b). The ITS region is one of the most reliable loci for identifying strains at species level (Hassan et al., 2019; Mazrou et al., 2020a). Thus, in this study, DNA sequencing of the 5.8S-ITS region was carried out for all isolates. By comparing the 


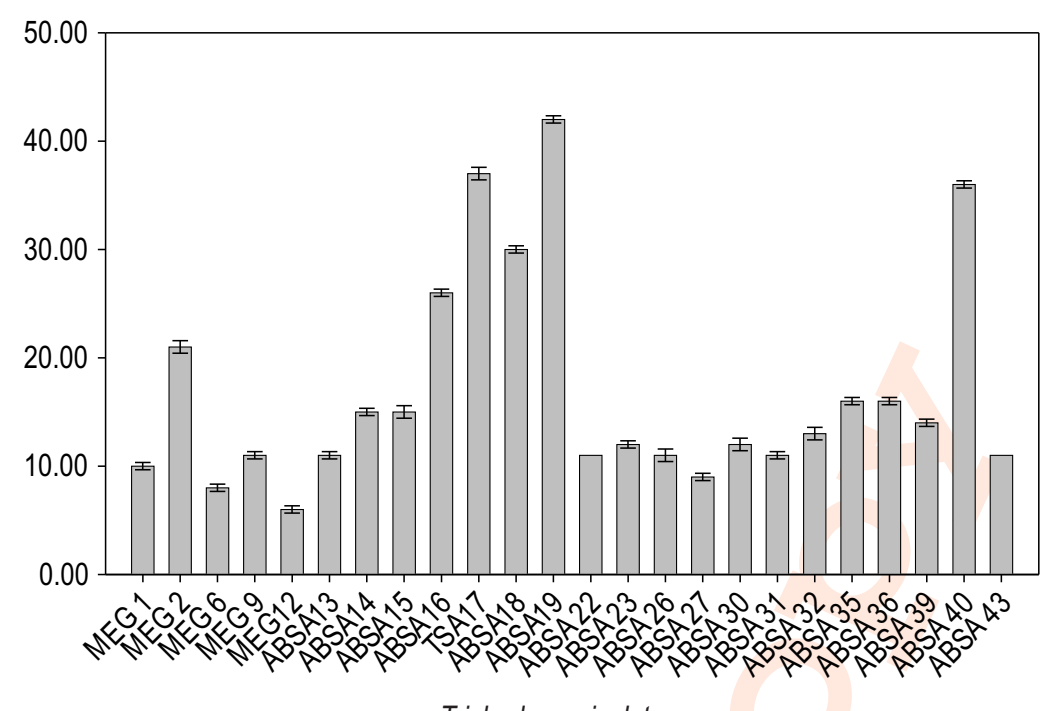

Trichoderma isolates

Fig. 1: Mycelial radial growth $(\mathrm{mm})$ of Trichoderma isolates based on their chitinase production ability using colloidal chitin media. Mean standard deviation is expressed in error bar $(n=3)$.

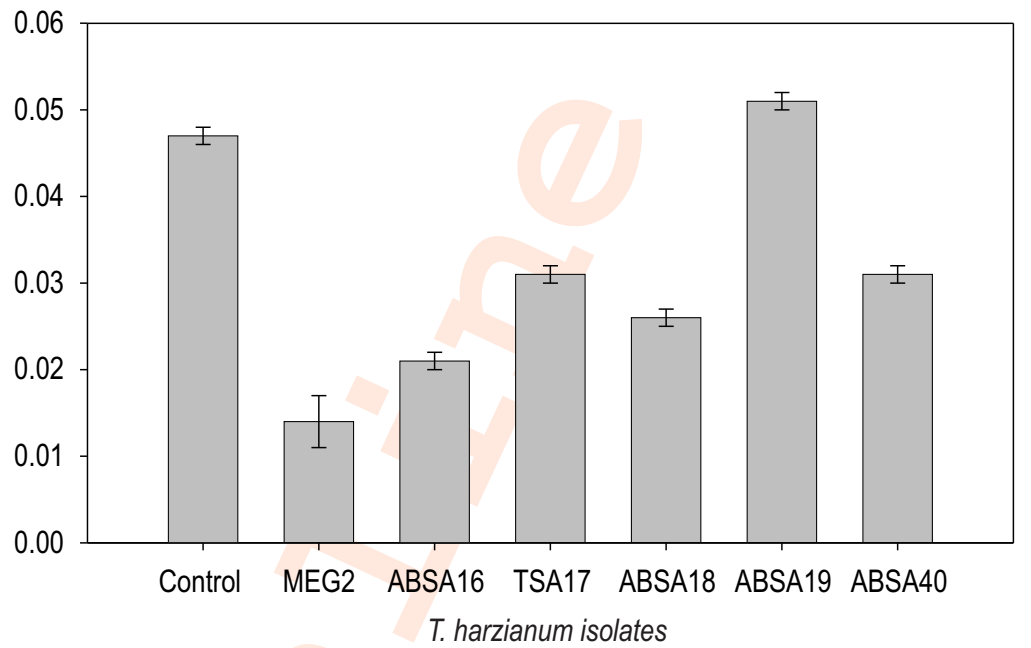

Fig. 2: Determination of total chitinase activity of six T. harzianum strains isolated from different location in Egypt and Saudi Arabia.

sequences of the 5.8S-ITS region to the sequences available on GenBank, all the Trichoderma isolates could be identified to species level with homology of at least 99\% (Filizola et al., 2019).

The total chitinase activity ranged between 0.014 and 0.051 units $\mathrm{ml}^{-1}$ across strains (Fig. 2). Strain ABSA19 showed the highest total chitinase activity of 0.051 units $\mathrm{ml}^{-1}$ among strains. This activity was comparable to that of the control (containing 0.050 unit $\mathrm{ml}^{-1}$ chitinase enzyme, Sigma, USA). The second highest chitinase activity of 0.031 units $\mathrm{ml}^{-1}$ was attributable to strains TSA17 and ABSA40. ABSA16 and ABSA18 strains had a relatively low chitinase activity of 0.021 and 0.026 units $\mathrm{ml}^{-1}$, respectively. The lowest total chitinase activity $(0.014$ units $\mathrm{ml}^{-1}$ ) was observed in strain MEG2. Induction of chitinase hydrolytic activity detected herein indicates that this chitinase may be involved in the mycoparasitism of $T$. harzianum toward plant-pathogenic fungi. In this context, chitin and $\beta$-1,3-glucans are known to be the structural components of fungal cell wall, suggesting that chitinase and $\beta-1,3$-glucanase produced by Trichoderma species may act as cell lysis enzymes during mycoparasitism (Mohamed et al., 2010; Hassan 2014; UrbinaSalazar et al., 2018). Furthermore, the antagonistic effects of six 

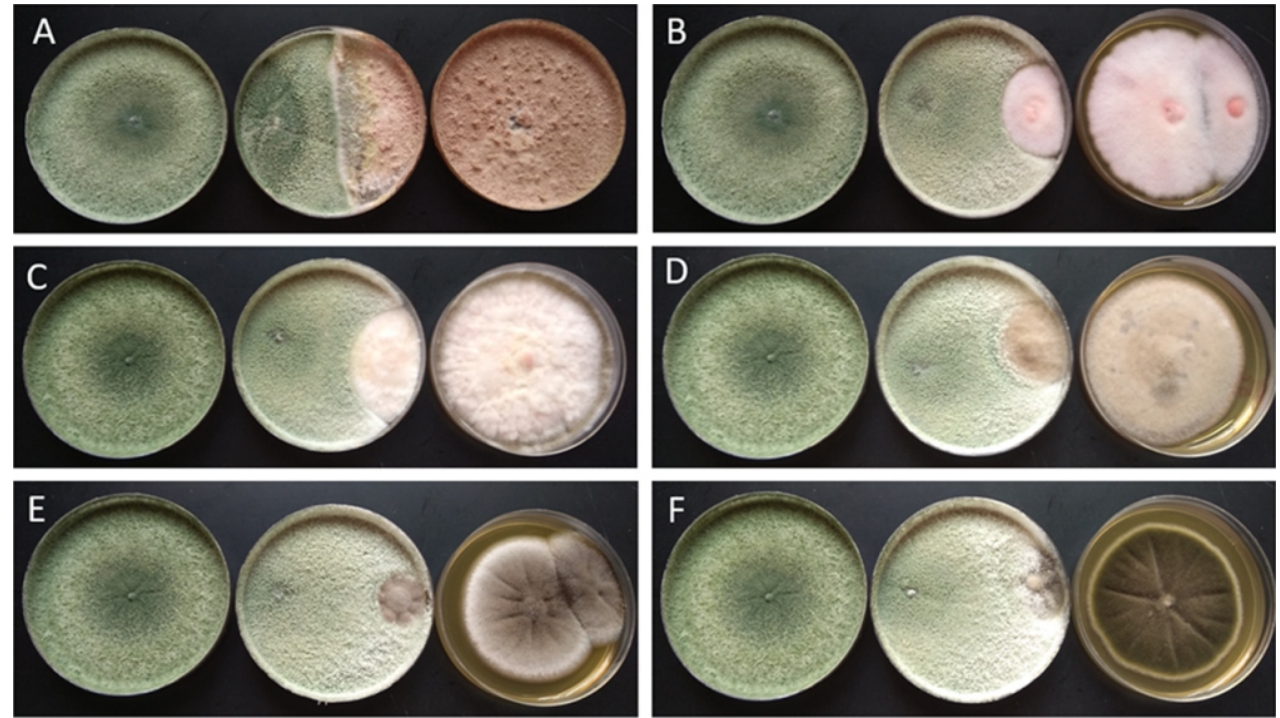

Fig. 3: Antagonistic activity of ABSA19 Trichoderma strain against: (A) Colletotrichum gossypii; (B) Fusarium oxysporium; (C) Rhizoctonia solani; (D) Fusarium fujikuroi; (E) Aspergillus calidoustus and (F) Alternaria brassicicola (on the left: pure culture of Trichoderma isolates, on the right: pure culture of pathogens and on the middle: the dual culture of pathogen and Trichoderma strain).

Trichoderma strains (MEG2, ABSA16, TSA17, ABSA18, ABSA19 and ABSA40) against six tomato plant pathogens (C. gossypii, $F$. oxysporum, F. fujikuroi, R. solani, A. calidoustus, and A. brassicicola) were evaluated. In all the dual culture plates tested, the contact zone showed curved pattern, with the concavity oriented toward the plant pathogen (Fig. 3). The negative control plates were inoculated only with the plant pathogen while the negative control plate inoculated only with Trichoderma strains. The average rates of percent inhibition (\%) of mycelial growth by the strains toward all six pathogens are listed in Table 3. All the Trichoderma isolates inhibited the mycelial growth of the pathogens, with percent reduction in pathogen growth varying between 70.8 and $92.5 \%$. The ABSA19 strain showed the highest inhibition of $C$. gossypii mycelial growth as compared to other isolates, with a percent inhibition of $78.9 \%$. The close second was strain ABSA40 (76.8\% inhibition), whereas TSA17 and MEG2 caused the lowest percent inhibition of $70.8 \%$.

The growth of $F$. oxysporum was inhibited significantly by ABSA19 (86.5\%) as compared to other strains, followed by ABSA18 and ABSA40 (85.6\%). Moreover, mycelial growth in $R$. solani was mostly inhibited by isolates ABSA19 (84.0\%), followed by ABSA16 (83.1\%). On the other hand, isolate ABSA19 showed the highest percent inhibition of $F$. fujikuroi mycelial growth as compared to other isolates, with a percent inhibition of $85.7 \%$, followed by isolate ABSA16 (82.9\%). A. calidoustus growth was significantly inhibited by ABSA16 (90.5\%), followed by isolate ABSA40 (88.5\%). The growth of $A$. brassicicola was inhibited significantly by isolate ABSA19 $(92.5 \%)$ rather than other isolates, followed by isolate ABSA40 (91.2\%), while ABSA18 caused the lowest percent inhibition of $88.1 \%$. All the strains showed antagonistic activity ranging from moderate to strong against plant pathogens. The ABSA19 strain manifested highest activity against all the pathogens and showing highest chitinase activity. The results support those obtained in the dual culture assay antagonistin abilities of these Trichoderma strains. The potency of Trichoderma may be attributed to the ability to produce toxic hydrophilic metabolites or lytic enzymes (Hassan 2014; Parmar et al., 2015; Mazrou et al., 2020b). These enzyme components, such as glucanase and chitinase, are released by Trichoderma strains at low levels. Therefore, it can act against pathogenic fungi before interacting with the two mycelia, thus increasing the antagonistic capacity of Trichoderma (Fahmi et al., 2012; Filizola et al., 2019). Enzymes chitinase and glucanase are produced by Trichoderma species, but these enzymes are mainly expressed in the presence of their respective substrates (chitin and glucan) (Gajera and Vakharia 2012; Rana et al., 2012; Hassan 2014; Abd-El-Kareem et al., 2019).

A more detailed picture of the development of coils and initiation of interactions among the tested pathogens and Trichoderma strains was obtained by SEM (Fig. 4). Coiling of pathogen hyphae was observed in ABSA19 Trichoderma strains, but only ABSA19 was selected for visualization via SEM. Scanning electron micrographs taken three days after inoculation showed complete colonization of $C$. gossypii with the ABSA19 strain (Fig. 4a). Examination of contact zone revealed that the parasitic hyphae had reached and grown on the surface of the pathogen via coiling and subsequent spore formation on $F$. oxysporum, F. fujikuroi, and R. solani (Fig. 4B - D). The observed growth pattern was followed by the formation of aspersorium-like structures that did not penetrate the cell walls of $A$. calidoustus 

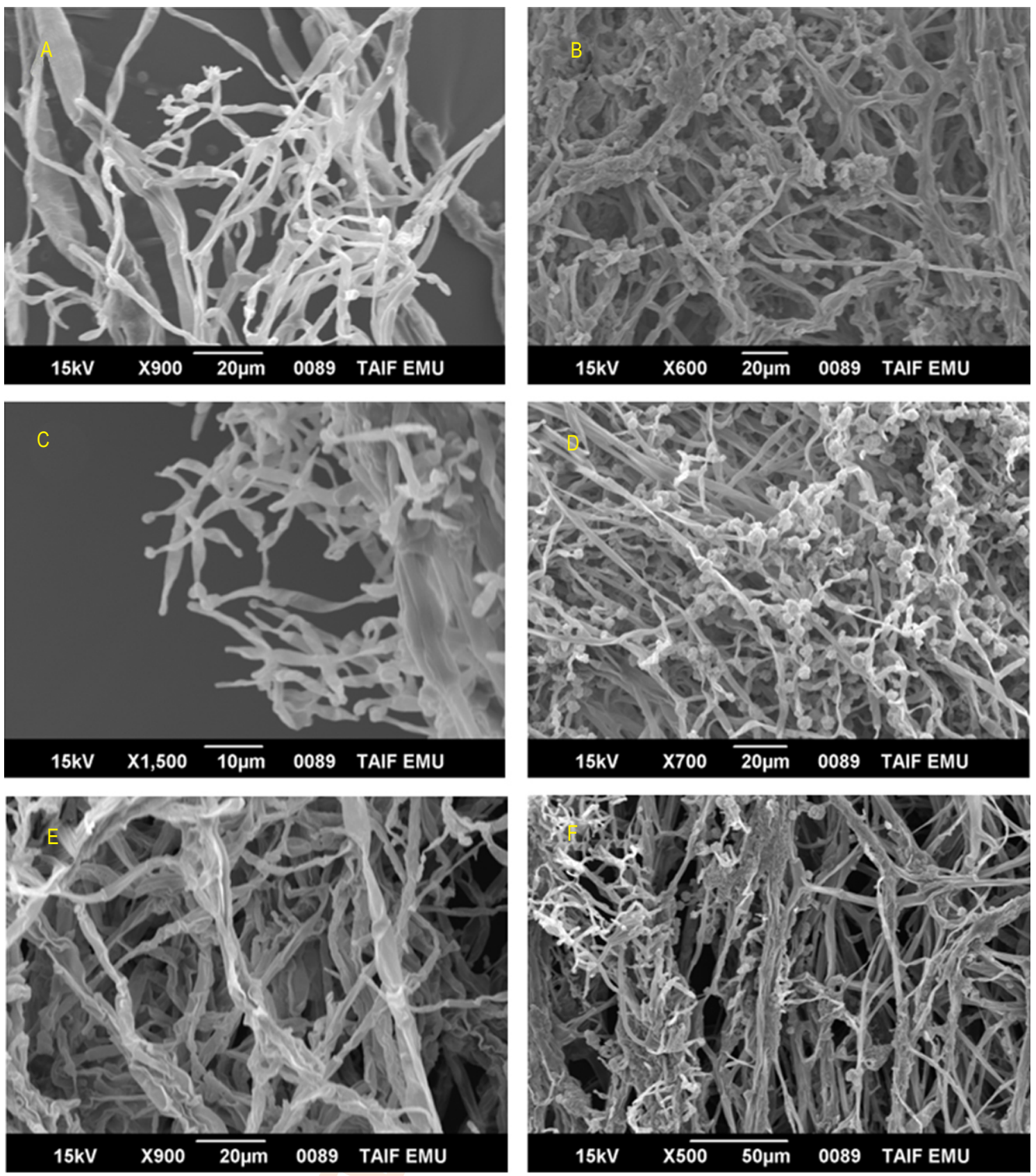

Fig. 4: Scanning electron micrographs showing antagonistic activity of ABSA19 strain. Coiling of Trichoderma isolates, spores formation over lytic enzymes of pathogens and seem to be capable of degrading the pathogen cell walls of (A) Colletotrichum gossypii; (B) Fusarium oxysporium; (C) Fusarium fujikuroi; (D) Rhizoctonia solani; (E) Aspergillus calidoustus and (F) Alternaria brassicicola.

and $A$. brassicicola (Fig. 4E, F). Pathogens invaded by parasitic hyphae started appeareing to disintegrate. In the current study, each fungal pathogen of plants responded differently to diffusible or volatile metabolites of strain ABSA19 in dual culture, is in agreement with the findings of Cooney and Lauren (1998), who reported that $T$. harzianum produces larger amount of 6-pentylapyrone in response to specific pathogens. This effect could be due to direct interaction and response of the antagonist to the presence of the pathogen. Additionally, it is possible that some pathogens can produce extracellular enzymes, proteins, or metabolites that cause the antagonist to abundantly generate antifungal metabolites. Accordingly, scanning electron micrographs were utilized to determine the damage inflicted on the pathogens' hypha. Coiling of pathogen hyphae was observed 

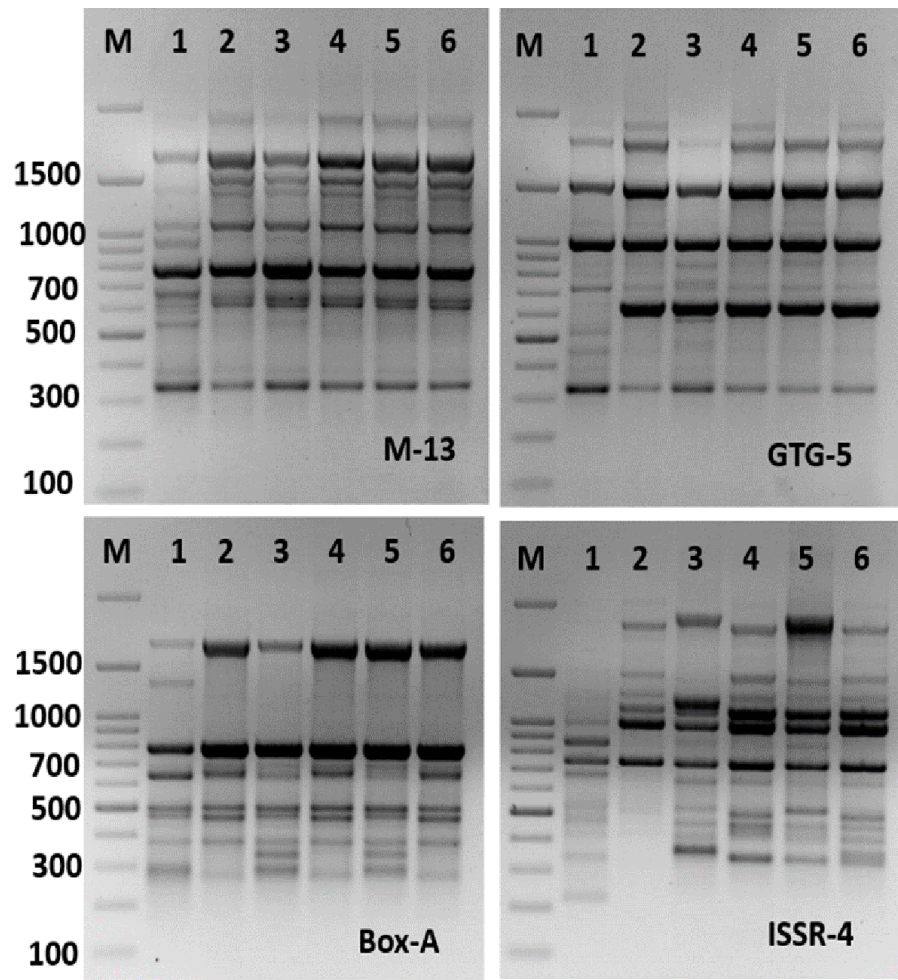

100

Box-A
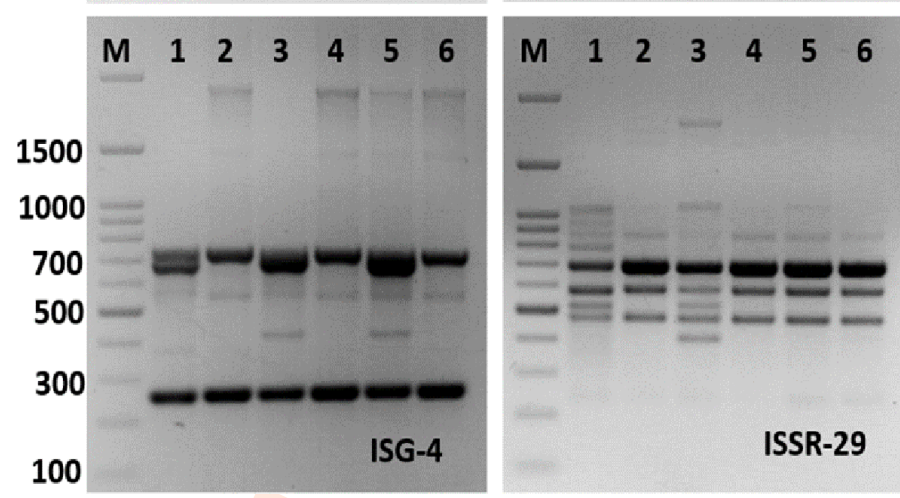

Fig. 5: ISSR-PCR profile of six $T$. harzianum samples (1=MEG2, 2=ABSA16, 3=TSA17, 4=ABSA18, 5=ABSA19 and 6=ABSA40) generated with the respective ISSR primers: M-13, GTG-5, Box-A, ISSR-4, ISG-4 and ISSR-29. The first lane in each panel corresponds to 100-bp molecular weight markers.

for most Trichoderma strains, but only Trichoderma strain ABSA19 was selected for visualization via SEM. The collapse of parasitic hypothecium has been reported as an effect of cellular enzymes on some pathogens, along with observations of coagulation, Trichoderma infiltration, and spore formation. In addition, the host's hyphae were found to completely disappear seven days after the inoculation (Hassan, 2014; Mazrou et al., 2020b). Lytic enzymes from Trichoderma strains can produce large amount of chitinase seem to be capable of degrading pathogens' cell wall. Mycoparasitism is an important and complex process in which Trichoderma spp. grow toward their hosts and attach and coil around the host hyphae, sometimes penetrating them (Zarei et al., 2011). Partial degradation of host cell wall was observed at later stages of this process (Hassan, 2014). The effects of cell wall degrading enzymes on the host have been reported previously using different ultrastructural and/or histochemical approaches (Hassan, 2014; Abd-El-Kareem et al., 2019; Mazrou et al., 2020b).

Finally, molecular characterization of Trichoderma strains was implemented by ISSR markers. ISSR markers have been used to study the genetic diversity and population dynamics of various T. harzianum strains (Hassan et al., 2014; Lakhani et al., 2016). A total of 133 fragments across the six isolates were 
obtained, of which 47 were polymorphic (35.3\%). A representative sample of six ISSRs profiles for six isolates are presented in (Fig. 5). The fragment size ranged between 130 and $3000 \mathrm{bp}$, with ISSR-4 showed the highest number fragments (18, Table 4), while ISG-4 yielded the lowest number of fragments (7, Table 4). Two specific fragments were detected in Trichoderma strain MEG2 with primers BoxA1 and ISSR-4 with molecular weight 1400 and $210 \mathrm{bp}$. Moreover, two additional specific fragments were detected in strain TSA17 with primer ISSR-29, with molecular weight 1800 and $400 \mathrm{bp}$. and one specific fragment was observed in TSA17 and ABSA19 using ISG-4 with about molecular wight $400 \mathrm{bp}$. ISSR analysis has previously been used to explore the genetic diversity among species and strains of Trichoderma (Lakhani et al., 2016; and Hassan et al., 2019; Mazrou et al., 2020a).

In this study, ISSR results indicated that Trichoderma strains were differed and collected from different geographic areas. Lakhani et al. (2016) developed ISSR markers to discriminate genetic diversity of two strains of Trichoderma spp. and their protoplast fusants. They found that the percent polymorphism for all strains was $88 \%$. The data obtained in the present study are consistent with the results of Hassan et al. (2014), who conducted the ISSR analysis, and the percent genetic polymorphism reached as much as $58.7 \%$ between Trichoderma species. The strains of $T$. harzianum with high chitinase activity displayed strong antagonistic activity against certain tomato pathogens, including Colletotrichum gossypii, Fusarium oxysporum, Fusarium fujikuroi, Rhizoctonia solani, Aspergillus calidoustus and Alternaria brassicicola using dual culture assays. The results obtained suggested that ABSA19 strain may be used as a biological control agent in agriculture and it may further be used in field experiments and also for the production of commercial fertilizers.

\section{Acknowledgments}

The authors extend their appreciation to the Deanship of Scientific Research at King Khalid University for funding this work through the Program of Research Groups under grant number (R.G.P 2/28/1440). The current work was also funded by Taif University Researchers Supporting Project number (TURSP2020/59), Taif university, Taif, Saudi Arabia.

\section{References}

Abd-El-Kareem, F., I.E. Elshahawy and M.M. Abd-Elgawad: Local Trichoderma strains as a control strategy of complex black root rot disease of strawberry in Egypt. Bull. Nat. Res. Cen., 43,160 (2019).

Aggarwal, C., S. Paul, V. Tripathi, B. Paul and M.A. Khan: Chitinolytic activity in Serratia marcescens (strain SEN) and potency against different larval instars of Spodoptera litura with effect of sublethal doses on insect development. Bio. Control, 60, 631-640 (2015).

Agrawal, T. and A. Kotasthane: Chitinolytic assay of indigenous Trichoderma isolates collected from different geographical locations of Chhattisgarh in Central India. SpringerPlus, 1,73 (2012).
Binod, P., C. Sandhya, P. Suma, G. Szakacs and A. Pandey: Fungal biosynthesis of endochitinase and chitobiase in solid state fermentation and their application to produce N-acetyl-Dglucosamine from colloidal chitin. Biores. Technol., 98, 2742-2748 (2007).

Carsolio, C., N. Benhamou, S. Haran, C. Cortés, A. Gutiérrez, I. Chet and A. Herrera-Estrella: Role of the Trichoderma harzianum endochitinase gene, ech42, in mycoparasitism. Appl. Environ. Microbiol., 65, 929-935(1999).

Cooney, J.M. and D.R. Lauren: Biotransformation of the Trichoderma metabolite 6-n-pentyl-2H-pyran -2-one (6PAP) by selected fungal isolates. J.Nat.Prod., 62,681-683 (1999).

Fahmi, A.I., A.D. Al-Talhi and M.M. Hassan: Protoplast fusion enhances antagonistic activity in Trichoderma spp. Nat. Sci., 10,100-106 (2012).

Fahmi, A.I., R.A. Eissa and K.A. El-Halfawi: Identification of Trichoderma spp. by DNA barcode and screening for cellulolytic activity. J. Microbiol. Biochem. Technol., 8, 202-209 (2016).

Filizola, P.B., M.C. Luna, A.F. de-Souza, I.L. Coelho, D. Laranjeira and G.M. Campos Takaki: Biodiversity and phylogeny of novel Trichoderma isolates from mangrove sediments and potential of biocontrol against Fusarium strains. Microb. Cell Fact., 18, 89 (2019).

Gajera, H.P. and D.N. Vakharia: Molecular and biochemical characterization of Trichoderma isolates inhibiting a phytopathogenic fungi Aspergillus niger Van Tieghem. Physiol. Mol. Plant Pathol., 74, 274-282 (2010).

Gajera, H.P. and D.N. Vakharia: Production of lytic enzymes by Trichoderma isolated during in-vitro antagonism with Aspergilus niger, the causal agent of collar rot of peanut. Brazilian J. Microbiol., 43, 43-52 (2012).

Goswami, J., R.K. Pandey, J.P. Tewari and B.K. Goswami: Management of root knot nematode on tomato through application of fungal antagonists, Acremonium strictum and Trichoderma harzianum. J. Envir. Sci. Hlth., 43, 237-240 (2008).

Hassan, M.M., A. Gaber and E.I. El-Hallous: Molecular and morphological characterization of Trichoderma harzianum from different Egyptian soils. Wulfenia J., 21, 80-96 (2014).

Hassan, M.M., M.A. Al-Awady, H.N. Lakhani and A.E. El-Tarras: Improvement of biological control activity in Trichoderma against some grapevine pathogens. Life Sci. J., 10, 2275-2283 (2013).

Hassan, M.M., M.A. Farid and A. Gaber: Rapid identification of Trichoderma koningiopsis and Trichoderma longibrachiatum using sequence characterized amplified region markers. Egyp. J. Biol. Pest Con., 29,13 (2019).

Hassan, M.M.: Influence of protoplast fusion between two Trichoderma spp. on extracellular enzymes production and antagonistic activity. Biotechnol. Biotechnol. Equip., 28, 1014-1023 (2014).

Karlsson, M., K. Ihrmark, N. Asmail, W. Ubhayasekera, P. Melin and J. Stenlid: Comparative molecular evolution of Trichoderma chitinases in response to mycoparasitic interactions. Evol. Bioinform., 6, 1-26 (2010).

Lakhani, H.N., D.N. Vakharia, M.M. Hassan and R.A. Eissa: Fingerprinting and molecular comparison among two parental strains of Trichoderma spp. and their corresponding fusants produced by protoplast fusion. Biotechnol. Biotechnol. Equip., 30, 1065-1074 (2016)

Mazrou, Y.S., A.H. Makhlouf, E.R. Elbealy, M.A. Salem, M.F. Awad, M.M. Hassan and M. Ismail: Molecular characterization of phosphate solubilizing fungi Aspergillus niger and its correlation to sustainable agriculture. J. Environ. Biol., 41, 592-599 (2020a).

Mazrou, Y.S.A., A.H. Makhlouf, M.M. Elseehy, M.F. Awad and M.M. Hassan: Antagonistic activity and molecular characterization of 
biological control agent Trichoderma harzianum from Saudi Arabia. Egyp. J. Biol. Pest Con., 30, 1-8 (2020b).

Mohamed, H.A., M.H. Wafaa and A.G. Attallah: Genetic enhancement of Trichoderma viride to over produce different hydrolytic enzymes and their biocontrol potentially against root rot and white mold diseases in plants. Agric. Biol. J. N. Am., 1, 273-284 (2010).

Navazio, L., B. Baldan, R. Moscatiello, A. Zuppini, S.L. Woo, P. Mariani and M. Lorito: Calcium-mediated perception and defense responses activated in plant cells by metabolite mixtures secreted by the biocontrol fungus Trichoderma atroviride. BMC Plant Biol., 7,41 (2007).

Parmar, H.J., M.M. Hassan and N.P. Bodar: In-vitro antagonism between phytopathologic fungi Sclerotium rolfsii and Trichoderma strains. Int. J. Appl. Sci. Biotechnol., 3, 16-19 (2015).

Rana, I.A., H. Loerz, W. Schaefer and D. Becker: Over expression of chitinase and chitosanase genes from Trichoderma harzianum under constitutive and induced promoters in order to increase disease resistance in wheat (Triticum aestivium). Mol. Plant Breed., 3, 37-49 (2012).

Roberts, W.K. and C.P. Selitrennikoff: Plant and bacterial chitinases differ in antifungal activity. J. Gen. Microbiol., 134,169-176 (1988).

Rojas-Avelizapa, L.I., M. Gomez-Ramırez and R. Cruz-Camarillo: Fermentation of shrimp waste to produce proteochitinolytic enzymes and insecticidal crystals. In: Chitosan in Pharmacy and Chemistry (Eds.: R.A.A. Muzzarelli and C. Muzzarelli). Atec, Italy, pp. 479-487 (2001).

Schickler, H., S. Haran, A. Oppenheim and I. Chet: Induction of the
Trichoderma harzianum chitinolytic system is triggered by the chitin monomer $\mathrm{N}$-acetyl glucosamine. Mycol. Res., 102, 1224-1226 (1998).

Shahid, M., M. Srivastava and A. Sharma: Morphological, molecular identification and SSR marker analysis of a potential strain of Trichoderma/Hypocrea for production of a bioformulation. J. Plant Pathol. Microbiol., 4, 204-210 (2013).

Sharma, K., A.K. Mishra and R.S. Misra: Morphological, biochemical and molecular characterization of Trichoderma harzianum isolates for their efficacy as biocontrol agents. J. Phytopathol., 157, 51-56 (2009).

Snedecor, G.W. and W.G. Cochran: Statistical Methods. $8^{\text {th }}$ Edn., lowa State University Press, Ames, lowa (1989).

Urbina-Salazar, A., A.R. Inca-Torres and G. Falcón-García, P. CarboneroAguilar, B. Rodríguez-Morgado, J.A. del-Campo, J. Parrado and J. Bautista: Chitinase production by Trichoderma harzianum grown on a chitin-rich mushroom by product formulated medium. Waste Biomass Valori., 10, 2915-2923 (2018).

Vinale, F., E.L. Ghisalberti, K. Sivasithamparam, R. Marra, A. Ritieni, R. Ferracane, S. Woo and M. Lorito: Factors affecting the production of Trichoderma harzianum secondary metabolites during the interaction with different plant pathogens. Lett. App. Microbiol., 48, 705-711 (2009).

Zarei, M., S. Aminzadeh, H. Zolgharnein, A. Safahieh, M. Daliri, K.A. Noghabi, A. Ghoroghi and A. Motallebi: Characterization of a chitinase with antifungal activity from a native Serratia marcescens B4A. Br. J. Microbiol., 42,1017-1029 (2011). 